
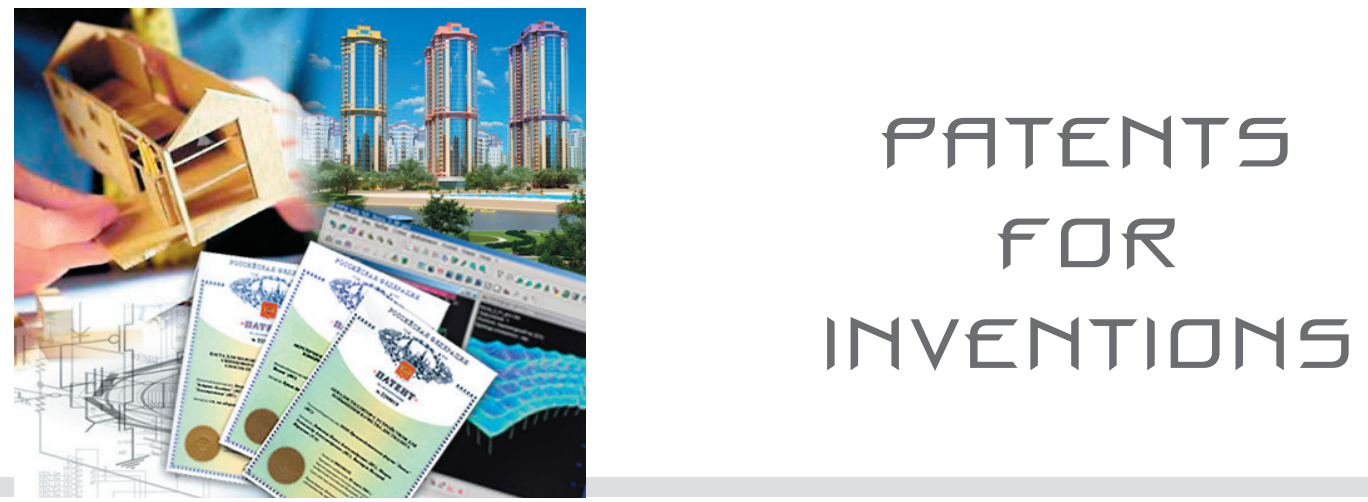

удК 62; 69

VLASOV Vladimir Alexeevich, Ph.D. in Engineering, Expert, International Academy of Engineering;

Gazetny per., block 9, bld.4, Moscow, 125009, Russian Federation, e-mail: info@nanobuild.ru

\title{
THE INVENTIONS IN NANOTECHNOLOGICAL AREA INCREASE EFFICIENCY OF CONSTRUCTION, HOUSING AND COMMUNAL SERVICES AND ADJACENT ECONOMIC FIELDS
}

The review gives brief description of inventions in nanotechnological area: the production method for silver nanoparticles with modified ligand shell in highviscosity matrix (RU 2526967); structures containing molecular structures with high aspect ratio and the production methods for them (RU 2526969); preconcentrator of the samples (RU 2526972); antifrictional composition (RU 2526989); conglutination composition for metal articles (RU 2526991); thin dispersed organic suspension of metal/carbon nanocomposite and the production method for it (RU 2527218); composite ion-exchange membrane (RU 2527236); pigment based on modified titanium dioxide powder (RU 2527262); the method of production of microballs and microspheres (RU 2527427); the method for strengthening metal products with nanostructured surface layers (RU 2527511); the method of production of sensitive element of gas detector with carbon nanotubes (RU 2528032); cutting plate (RU 2528288) etc. The inventions in the nanotechnological area can cause significant effects on construction, housing and communal services and adjacent fields of economy: reduced hardening time and increased durability of adhesive joints, increased wear-resistance of cutting plates, increased strength of materials under compressive forces, descreased detail tearing, etc. 
For example, composition for glueing metal products (RU 2526991) contains anaerobic mastic AH-111 and the filler - carbon nanotubes «Taunit-M». The invention shortens hardening time and increases the durability of adhesive joints. Cutting plate (RU 2528288) contains the base made of hard alloy and sprayed on it wear-resistant layer of nanostructured tungsten carbide and nanostructured niobium carbide which grain size is $20-50 \mathrm{~nm}$, and their ratio, mass. \% : nanostructured tungsten carbide 90, nanostructured niobium carbide - the rest. That increases wear-resistance of cutting plates, especially in hard cutting modes.

Key words: nanotechnologies, nanomaterials, nanocomposites, nanocomposites, nanostructures, nanotubes.

DOI:dx.doi.org/10.15828/2075-8545-2014-6-5-93-113

\section{The production method for silver nanoparticles with modified ligand shell in high-viscosity matrix (RU 2526967)}

The invention refers to nanotechnology and can be used for effective change of optoelectronic properties of ensemble of silver particles covered with ligand coating in adhesive environments and films. The invention can be used for production of photon crystals, optical filters and a new generation of Raman lasers. To obtain highly ordered ensembles of silver nanoparticles with ligand coating one need to add $3-6 \mathrm{~mol} / \mathrm{g}$ of silver nitrate solution, $15 \mathrm{~mol} / \mathrm{g}$ of natrium oleate and $10 \mathrm{~mol} / \mathrm{g}$ of natrium borane in high-viscosity water solution of polyvinyl alcohol or gelatin. The reaction runs without mixing. The invention allows obtaining ensembles of nanoparticles covered with ligand coating with low level of aggregation in high-viscosity environments and films [1].

\section{Structures containing molecular structures with high aspect ratio and the production methods for them}

(RU 2526969)

The invention refers to the film laying technologies and deals with the structures comprising molecular structures with high aspect ratio (BACM- 
structures), and the production method for them. Nanocarbon film structure containing BACM-structures in which the structure has essentially flat network made of random oriented BACM-structures and the base which is in contact with the network. The base has a hole, along peripheral zone of the hole the network contacts with the base in such a way that middle part of the network is not fixed on the base. The method includes phases of production of flat network from BACM-structures on the preparatory base near or in contact with the base with the hole by means of spraying BACMstructures on the preparatory base and in the hole of the base, and removing preparatory base from the network. The invention provides creation of new types of structures containing BACM-structures [2].

\section{Preconcentrator of the samples (RU 2526972)}

The invention refers to preconcentrator of the samples which can be used for absorption and desorption of gas samples. The preconcentrator contains metal nanocomplexes with carbon nanotubes. And metal in metal nanocomplexes with carbon nanotubes is one or more metals selected from the group consisting of cobalt, copper, nickel, titanium, silver, aluminium, iron, tungsten and their aqueous salts or hydrates. The preconcentrator may have sample concentration unit which comprises mentioned nanocomplexes and a hole for introduction of gas sample, a supplier of dried gas and gas and analytical system connected with the preconcentrator of the samples. Achieved technical result is that efficiency of gas concentration is increased [3].

\section{Antifrictional composition (RU 2526989)}

The invention refers to the filled polymer materials, in particular to the materials based on carbon woven reinforcing material and epoxy thermosetting polymer binder. Antifrictional material includes carbon fabric of fibers with the fixed size of crystalline particles by basal plane and package thickness with fixed number of basal planes soaked in composition of epoxy resin, metal powder of tin or tin babbit with dispersity 5-100 $\mu \mathrm{m}$, molybdenum disulfide with dispersity $0,6-0,7 \mu \mathrm{m}$, taken 
in the proportion 1:2 respect to metal powder. Components of metal are taken in the following ratio (mass.\%): carbon fabric 46,3-56,6, epoxy resin $37,8-46,3$, powder of tin or tin babbit 3,8-4,9, molybdenum disulfide 1,9-2,45, and the total content of metal powder and molybdenum disulfide is 5,7-7,35 mac.\%. The invention increases compressive strength of material, coefficient of elasticity and decreases intensity of tiring for friction details [4].

\section{Conglutination composition for metal articles (RU 2526991)}

The invention refers to mechanical engineering and machinery repairs, in particular metal details and units. The conglutination composition for metal articles contains anaerobic mastic AH-111 and nanofillercarbon nanotubes «Taunit-M». The invention shortens hardening time and increases the durability of adhesive joints [5].

\section{Thin dispersed organic suspension of metal/carbon nanocomposite and the production method for it (RU 2527218)}

The invention refers to production of ultra-dispersed organic suspensions containing metal/carbon nanocomposite and can be used to create functional polymer materials. Mechanically ground powder of metal/ carbon nanocomposite which is nanoparticles of $3 \mathrm{~d}$ metal (such as copper, nickel or iron) stabilized in carbon nanofilm structures is mechanically milled with portionally added organic compound according to ratio $3: 1$. The obtained mixture is dispersed by ultrasound for the time period which is equivalent to maximal ratio of peak intensities on infrared spectrum when the wave numbers of obtained suspension and organic compound are the same. Ethyl alcohol, toluene, acetone and isomethyltetrahydrophthalic anhydride, mixtures of organic substances are used as organic environments. The technical result is produced suspension based on organic compound and metal/carbon nanocomposite with adjustable activity which can be controlled by the infrared spectroscopy method [6]. 


\section{Composite ion-exchange membrane (RU 2527236)}

The invention refers to technology of production of composite ion-exchange membranes possessing property of sorbtion selectivity and nitrateanion transfer. Composite ion-exchange model was proposed. The model is characterized by increased mobility of nitrate-anions and increased constant of ion exchange in respect to nitrate-anion. The membrane contains ion-exchange polymer matrix which is modified in volume or gradient with nanoparticles of cerium oxide. The invention provides efficient use of produced membrane in the treatment processes of different solutions, including liquid food, from nitrate-anion [7].

\section{Pigment based on modified titanium dioxide powder (RU 2527262)}

The invention refers to the pigment of light-reflective coatings. The pigment contains the mixture of titanium dioxide particles of micron size and zirconium dioxide particles. The concentration of zirconium dioxide nanoparticles is chosen within the range $0,5-5,0$ mass. $\%$. The mixture is stirred with addition of distilled water and then this solution is evaporated for 6 hours under the temperature $150^{\circ} \mathrm{C}$, ground, heated for 2 hours under the temperature $800^{\circ} \mathrm{C}$, milled. The invention increases radiation resistance [8].

\section{The method of production of microballs and microspheres (RU 2527427)}

The invention refers to chemical industry and can be used in the production of glass balls both single and hollow ones, for example, for filters of different purpose, light-reflective devices. The technical task of the invention is to increase performance and safety of manufacturing process. The particles of carbonyl iron (magnetite which size is 5,0-10,0 nm and coated with tamol based on oleic acid) are loaded in kerosene. Then kerosene with nanoparticles of carbonyl iron is sprayed in the form of drops $(20-30 \mu \mathrm{m})$ through the nozzle into the chamber with three-phase electric winding which creates spiral rotating magnetic field. Into the same chamber glasspowder is delivered by compressed air and it is grasped by the 
kerosene drops which are rotating in magnetic field. After that it gets to the first zone of low intensivity of microwave oven where nanoparticles of carbonyl iron are heated up to $700-800^{\circ} \mathrm{C}$, as a result: kerosene decays and nanoparticles of carbonyl iron settle on the surface of glasspowder particles. With the further movement of glasspowder particles with nanoparticles of carbonyl iron the temperature of nanoparticles rises to $1300-1350^{\circ} \mathrm{C}$. The glass melts and being under molecular forces travels around all volume and forms microballs which are cooled later, nanoparticles of carbonyl iron are recovered and attracted to the poles of constant electric magnet [9].

\section{The method for strengthening metal products with nanostructured surface layers (RU 2527511)}

The invention refers to the methods for surface strengthening of metal materials by forming nanosize coatings caused by laser radiation and can be applied in different industries to produce wear-resistant and antifrictional coatings. The formation of nano-size superficial coating is performed by treating surface of metal articles with doping alloy used in the form of fine-dispersed powder. Irradiation of surface by means of focused optical thermal beam of high energy quantum generator is performed by moving laser beam with the step 25 micrometer and with the power, enough for dotted melting of doping alloy which consists of nanocomposite systems; a lay of doping alloy is alloyed into the treated article. Then the surface of the treated detail is cooled by the current of compressed air under the temperature $20^{\circ} \mathrm{C}$ and pressure $8 \mathrm{kPa}$ for crystallization of doping alloy on the metal surface of the article providing additional adhesion between the dopping alloy and cooled surface of the article without changing surface structure and with the formation of layer of dopping alloy with nitride and/or carbide matrix with nanocomposite structure on it. The power of laser radiation is defined by the expression $\mathrm{P}=1 \cdot 10^{-2} \cdot \mathrm{V} \cdot \mathrm{C} \cdot \mathrm{T} / \mathrm{L}$, where $\mathrm{P}$ - power of laser radiation, Watt, $1 \cdot 10^{-2}-$ constant, $\mathrm{V}$ - speed of laser beam on the surface, $\mathrm{mm} /$ second, $\mathrm{C}$ - heat capacity of dopping alloy, $\mathrm{J} / \mathrm{K}$, $\mathrm{T}$ - melting temperature of dopping alloy, $\mathrm{K}, \mathrm{L}-$ thickness of layer of dopping alloy, mm. The invention results in increased quality of the coatings which is created on the detail surface and which possess high heat-, corrosion- and erosion-resistance [10]. 


\section{The method of production of sensitive element of gas detector with carbon nanotubes (RU 2528032)}

The invention refers to gas analysis and can be also used to control toxic and explosive gases in scientific and engineering areas where the analysis of atmosphere is needed. According to invention semiconductor sensitive element is an isolating base with preliminary sprayed contacts. Application of film-forming aqueous alcoholic solution $\mathrm{SnCl}_{2}$ with carbon nanotubes on this base forms nanocomposite layer of tin dioxide. The sensitive element produced in this way is dried within 10 minutes under the temperature $150^{\circ} \mathrm{C}$ and then is exposed to stabilizing bakeout in the open air within 30 minutes under the temperature not less than $370^{\circ} \mathrm{C}$ to form nanocrystall structure. The aim of the invention is to increase gas sensibility and sensor element selectivity.

\section{Cutting plate (RU 2528288)}

The invention refers to the mechanical engineering, in particular to the metal-working. Cutting plate has a base of hard alloy and sprayed on it wear-resistant layer of nanostructured tungsten carbide and nanostructured niobium carbide which grain size is $20-50 \mathrm{~nm}$, and their ratio, mass. \%: nanostructured tungsten carbide 90, nanostructured niobium carbide - the rest. That increases wear-resistance of cutting plates, especially in hard cutting modes.

The specialists may be also interested in the following nanotechnological inventions:

- Reinforced flaked element made of natural or conglomerate stone and its multilayer protective coating (RU 2520193) [13];

- Fine organic suspension of carbon metal-containing nanostructures and the method to produce it (RU 2515858) [13];

- The method of production of carbon nanomaterial (RU 2509053) [14];

- The method of production of nanodispersed metal powders and alloys of them (RU 2509626) [14]; 
- The method to produce nanopowder of zinc oxide with the surface modification for the use in construction sealing materials (RU 2505379) [15];

- The method to produce polymer composition (RU 2506283) [15];

- The method of dispersion of nanoparticles in epoxy resin (RU 2500706) [16];

- The method to produce nanosuspension for manufacturing polymer nanocomposite (RU 2500695) [16];

- Dispersion of Carbon Nanotubes (RU 2494961) [17];

- Building Structures Reinforcement Composition (RU 2493337) [17];

- Nanostructured thermoelectric material (RU 2528338) [18];

- The method of production of absorbing coating for solar heating, coating and its application (RU 2528486) [19];

- The method of production of flaky material (RU 2528581) [20];

- The method of production of modifier for aluminium alloys (RU 2528598) [21];

- The method of production of composite materials based on silicon oxide (RU 2528667) [22];

- The method of production of nanosize lithium titanate powder (RU 2528839) [23];

- The modification method for carbon nanotubes (RU 2528985) [24].

\section{Dear Colleagues!}

THE REFERENCE TO THIS PAPER HAS THE FOLLOWING CITATION FORMAT:

Vlasov V.A. The inventions in nanotechnological area increase the efficiency of construction, housing and communal services and adjacent economic fields. Nanotehnologii v stroitel'stve $=$ Nanotechnologies in Construction. 2014, Vol. 6, no. 5, pp. 93-113. Available at: http://nanobuild.ru/en_EN/ (Accessed ). (In Russian). 


\section{References:}

1. Patents and inventions registered in RF and USSR [Electronic source]. - Access mode: http://www.findpatent.ru/patent/252/2526967.html (date of access: 18.08.14).

2. Patents and inventions registered in RF and USSR [Electronic source]. - Access mode: http://www.findpatent.ru/patent/252/2526969.html (date of access: 18.08.14).

3. Patents and inventions registered in RF and USSR [Electronic source]. - Access mode: http://www.findpatent.ru/patent/252/2526972.html (date of access: 18.08.14).

4. Patents and inventions registered in RF and USSR [Electronic source]. - Access mode: http://www.findpatent.ru/patent/252/2526989.html (date of access: 18.08.14).

5. Patents and inventions registered in RF and USSR [Electronic source]. - Access mode: http://www.findpatent.ru/patent/252/2526991.html (date of access: 18.08.14).

6. Patents and inventions registered in RF and USSR [Electronic source]. - Access mode: http://www.findpatent.ru/patent/252/2527218.html (date of access: 18.08.14).

7. Patents and inventions registered in RF and USSR [Electronic source]. - Access mode: http://www.findpatent.ru/patent/252/2527236.html (date of access: 18.08.14).

8. Patents and inventions registered in RF and USSR [Electronic source]. - Access mode: http://www.findpatent.ru/patent/252/2527262.html (date of access: 18.08.14).

9. Patents and inventions registered in RF and USSR [Electronic source]. - Access mode: http://www.findpatent.ru/patent/252/2527427.html (date of access: 18.08.14).

10. Patents and inventions registered in RF and USSR [Electronic source]. - Access mode: http://www.findpatent.ru/patent/252/2527511.html (date of access: 18.08.14).

11. Patents and inventions registered in RF and USSR [Electronic source]. - Access mode: http://www.findpatent.ru/patent/252/2528032.html (date of access: 18.08.14).

12. Patents and inventions registered in RF and USSR [Electronic source]. - Access mode: http://www.findpatent.ru/patent/252/2528288.html (date of access: 18.08.14).

13. Vlasov V.A. Inventions in the nanotechnological area considerably increase wear- and chemical resistance of construction products. Nanotehnologii v stroitel'stve $=$ Nanotechnologies in Construction. 2014, Vol. 6, no. 4, pp. 66-88. Available at: http://nanobuild. $\mathrm{ru} / \mathrm{en} \_\mathrm{EN} /$ (date of access: 18.08.14). (In Russian).

14. Vlasov V.A. Nanotechnological inventions considerably improve performance characteristics of concretes, polymers, metals and other materials. Nanotehnologii v stroitel'stve $=$ Nanotechnologies in Construction. 2014, Vol. 6, no. 3, pp. 77-95. Available at: http:// nanobuild.ru/en_EN/(date of access: 18.08.14). (In Russian).

15. Vlasov V.A. Inventions in the nanotechnological area provide improved performance characteristics of different sealing polymer materials used in construction. Nanotehnologii v stroitel'stve $=$ Nanotechnologies in Construction. 2014, Vol. 6, no. 2, pp. 78-107. Available at: http://nanobuild.ru/en_EN/ (date of access: 18.08.14). (In Russian).

16. Vlasov V.A. Inventions in the nanotechnological area provide increased resistance of construction materials and products to operationalload. Nanotehnologii v stroitel'stve $=$ Nanotechnologies in Construction. 2014, Vol. 6, no. 1, pp. 68-90. Available at: http://nanobuild.ru/en_EN/(date of access: 18.08.14). (In Russian).

17. Vlasov V.A. Inventions in the nanotechnological area provide increased resistance of construction materials and products to operational load. Nanotehnologii v stroitel'stve $=$ 
Nanotechnologies in Construction. 2013, Vol. 5, no. 6, pp. 126-140. Available at: http:// nanobuild.ru/en_EN/(date of access: 18.08.14). (In Russian).

18. Patents and inventions registered in RF and USSR [Electronic source]. - Access mode: http://www.findpatent.ru/patent/252/2528338.html (date of access: 18.08.14).

19. Patents and inventions registered in RF and USSR [Electronic source]. - Access mode: http://www.findpatent.ru/patent/252/2528486.html (date of access: 18.08.14).

20. Patents and inventions registered in RF and USSR [Electronic source]. - Access mode: http://www.findpatent.ru/patent/252/2528581.html (date of access: 18.08.14).

21. Patents and inventions registered in RF and USSR [Electronic source]. - Access mode: http://www.findpatent.ru/patent/252/2528598.html (date of access: 18.08.14).

22. Patents and inventions registered in RF and USSR [Electronic source]. - Access mode: http://www.findpatent.ru/patent/252/2528667.html (date of access: 18.08.14).

23. Patents and inventions registered in RF and USSR [Electronic source]. - Access mode: http://www.findpatent.ru/patent/252/2528839.html (date of access: 18.08.14).

24. Patents and inventions registered in RF and USSR [Electronic source]. - Access mode: http://www.findpatent.ru/patent/252/2528985.html (date of access: 18.08.14). 